\title{
Organoleptic and physicochemical properties of fat of some deer in Primorsky Krai
}

\author{
Evgeny Korotkov ${ }^{1}$, Elena Lyubchenko ${ }^{1, *}$, and Irina Korotkova ${ }^{1}$ \\ ${ }^{1}$ Primorskaya State Agricultural Academy, Blyukhera ave. 44, Ussuriysk, Primorsky Krai, 692510, \\ Russia
}

\begin{abstract}
Meat of wild animals has high nutritional and dietary properties and has always been considered a healthy food, since wild animals eat natural food. The conducted studies allowed determining the organoleptic and some physicochemical properties of water deer fat in comparison with sika deer fat for the first time.
\end{abstract}

\section{Introduction}

In this paper, a comparative analysis of the fat indicators of water deer and sika deer, which differ in organoleptic characteristics, in melting temperature, as well as in the content of saturated and unsaturated fatty acids, was made for the first time. Organoleptic and physicochemical indicators of fat are used to identify and determine the species during forensic-veterinary (biological, zoological) and veterinary-sanitary examination. It is planned to use deer, including water deer, as a food base for big cats in Primorsky Krai, which is especially important against the background of a decrease in the number of wild boars.

The fauna of the Primorsky Krai is represented by a variety of wild ungulates - sika deer, roe deer, red deer, wild boar, musk deer, goral - which are both the hunting and protected resources of the region. Ungulates also serve as food sources for protected big cats, such as the Amur tiger (Panthera tigris altaica) and the Far Eastern leopard (Panthera pardus orientalis). It may seem that land mammals are already quite well studied, especially those species of animals that are not rare, such as deer. But there is a completely unusual animal among them, the only representative of the genus of water deers - water deer (Hydropotes inermis), which has not been comprehensively studied in Russia.

Sika deer (Cervus Nippon), which is common in the south of Primorsky Krai, in China and Korea, belongs to the order of Artiodactyla ruminants and to the genus of red deer - an animal of average size with a light body type. Live weight of adult males is $120-140 \mathrm{~kg}$, females is 70-100 kg [1]. The habitats of wild sika deer in Primorye are oak-broad-leaved forests of the Manchurian type with good undergrowth [2]. Wild sika deer in Primorye eat at least 129 plant species, most of the diet is made up of leaves, buds, branches of trees and shrubs. They like to eat acorns, mushrooms, berries, leaves and buds of oak, linden, lianas, Manchurian aralia, in summer - sedge, parsley family and other tall grasses, as well as animals that are available to them [3]. In winter, they eat dry leaves, spruce bark, branches

\footnotetext{
${ }^{*}$ Corresponding author: 1yubchenkol@mail.ru
} 
of hazel, oak, shoots of young pines, aspen, elm, euonymus, alder buckthorn. On the seaside, deer lick salt from stones, eat zoster and kelp, which contain salt. Sika deer is a game animal, its meat is widely used for human consumption [2].

Water deer (Hydropotes inermis) belongs to the deer family, it is the only species of the genus of water deers. Only two habitats have survived - the subspecies Chinese water deer (Hydropotes inermis inermis) in the Shanghai region of southern China with a population of no more than 10,000 individuals, and the Korean water deer (Hydropotes inermis argyropus) on the border of South and North Korea [4]. In April 2019, a water deer was spotted by a camera trap in the south of the Land of the Leopard National Park [5]. Subsequently, a stuffed water deer represented as a "musk deer from the Khasan region" [6] was discovered and described. The water deer is not large in size, with a short body and a small elongated head, a short neck, and large ears, pubescent from the inside. Its body length is $70-100$ centimeters, its body weight is from 9 to $15 \mathrm{~kg}$. It lives in grassy thickets along the banks of rivers and lakes and in swamps. It feeds mainly on coastal grass, duckweed, as well as leaves, young shoots of shrubs, sedges and reeds. To replenish trace elements and protein, it periodically uses mushrooms, rice from agricultural fields, and snails. In winter, it feeds on dry leaves, coastal dry grass, horsetail, buds and thin branches of small shrubs. In China, water deer meat is used for food purposes [7].

In order to survive the winter, an animal needs a whole set of nutrients and vitamins, which, in the course of fat metabolism, gradually accumulates in depot fat. According to A.S. Bogachev [3], the value of fat varies depending on the depth of its occurrence. The closer the fat lies to the surface of the body, the more unsaturated fatty acids, which are the most biologically active ones, are in it. The melting point decreases with an increase in the fat content of unsaturated fatty acids. That is, the deeper the fat lies in the body of the animal, the more refractory and less qualitative in composition it is. Subcutaneous fat contains more unsaturated fatty and volatile acids than visceral fat. This pattern is manifested in ungulates.

The biological activity of fats determines the ratio of unsaturated fatty acids to limiting ones. The higher this ratio, the more valuable the fat. The biologically active components of fat, which determine its high medicinal and nutritional value, are unsaturated fatty acids: oleic, linoleic and linolenic ones, synthesized by herbivorous wild animals from the feed [8]. In different parts of the body, fat is deposited that is characteristic of a particular type of animal. Therefore, the composition of fat, its melting point, and the content of fatty acids are not the same [3]. These indicators are used to judge the purity of the fatty product and for identification, which is of great importance for determining the species during the forensic-veterinary (biological, zoological) and veterinary-sanitary examination [9].

The authors of this paper were the first to study the fat of water deer (Hydropotes inermis) killed for the first time in the Khasansky district of the Primorsky Krai. Its organoleptic properties, some physical properties and fatty acid composition were determined in comparison with similar fat indicators of sika deer (Cervus nippon), as a permanent representative of the Primorsky Krai fauna.

The purpose of this study was to carry out a comparative analysis of the fat indicators of water and sika deer.

To achieve the goal, a number of tasks were set:

- to determine the organoleptic and physical characteristics of fat of water deer and sika deer;

- to determine the quality indicators of fat of water deer and sika deer.

\section{Materials and methods}


The objects of the study were the corpses of water deer (Hydropotes inermis) and sika deer (Cervus Nippon), which, in accordance with the order of the Ministry of Forestry and Wildlife Protection of the Primorsky Krai, were delivered for veterinary examination to the Center for Diagnostics of Animal Diseases of the Institute of Animal Science and Veterinary Medicine of the Primorskaya State Academy of Agriculture in 2020. Subcutaneous and visceral fat from water deer and sika deer served as the material for the study. Subcutaneous fat was taken from the back and chest area. Visceral fat included fat of the omentum and intestines.

Determination of the species, sex and age of the animal was carried out by comparison with literature sources $[1,10]$. To establish the order, family, genus, species, subspecies of the studied animal, the taxonomy of mammals was used [11]. The postmortem examination of internal organs was performed according to the methods proposed by Lyubchenko et al. [12].

The state of fat in the carcass was determined at the time of sampling by color, smell and consistency in accordance with the Russian State Standard GOST 7269-2015 (Meat. Sampling methods and organoleptic methods for determining freshness). The melting point of fat was determined by a method based on the ability of fat to pass from a solid state to a liquid state (GOST 8285-91 - Rendered animal fats. Acceptance rules and test methods). Quality indicators were determined as a percentage of the total fatty acids (GOST R 554832013 - Meat and meat products. Determination of fatty acid composition by gas chromatography). During the postmortem examination, digital photography was carried out using the SONY NEX-7 camera [13].

\section{Results}

\subsection{Organoleptic and physical characteristics of fat of water deer and sika deer}

In a female water deer aged 2 - 2.5 years, the subcutaneous fat has a light gray color with areas of dark gray color, dense consistency, does not crumble when crushed, is located in a small amount in the form of layers on the rib wall and on the peritoneum. The smell is not pronounced, characteristic of raw bacon. Visceral fat of water deer is represented by fat from the omentum and mesentery of the small and large intestines. The omentum and mesentery of the small intestine contain insignificant fat depots ranging from light yellow to light gray.

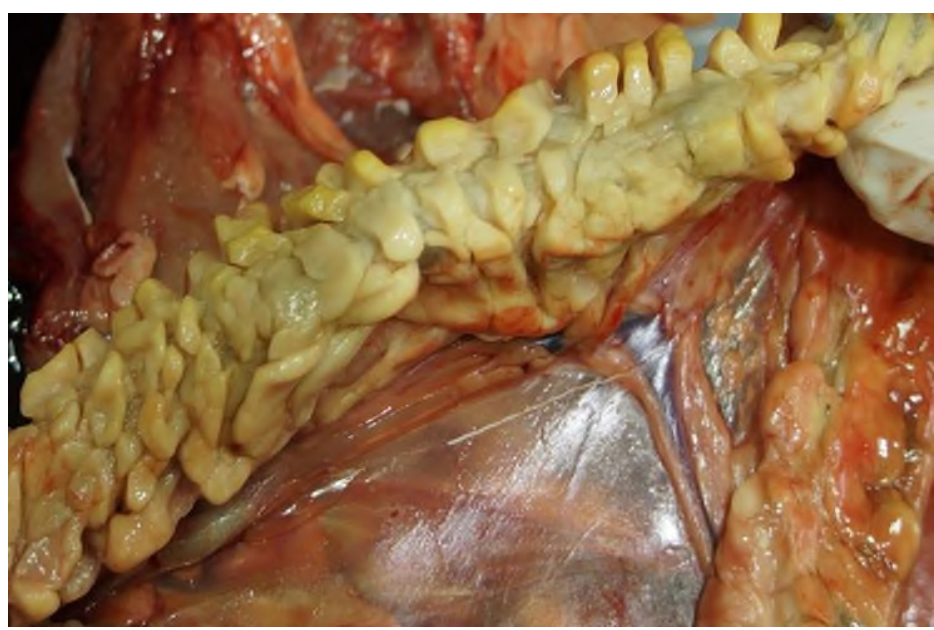


Fig. 1. Fat on the colon (cavity) of a water deer (photo by the authors).

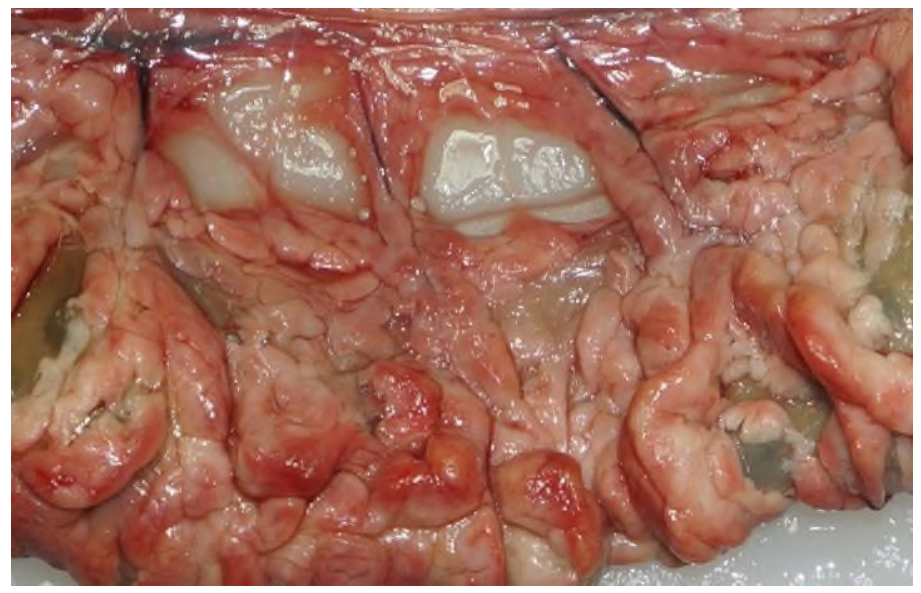

Fig. 2. Fat on the colon (cavity) of a sika deer (photo by the authors).

On the mesentery of the large intestine, the fat has a light yellow color, while the fat on the colon is yellow-gray in color and is located in the form of candle deposits, does not crumble when crushed (Fig. 1). The smell of fat from the intestines and omentum is slightly sour, the texture is dense. In the molten state, the subcutaneous fat of a water deer is transparent, and the cavity fat has an opaque yellowish suspension.

In a female sika deer at the age of 3-4 years, the subcutaneous fat has a light gray color, a hard consistency, largely expressed in the region of the back, ribs and tail. Among the muscular connective tissue layers, it is well expressed in the abdomen and chest wall, giving the meat a marble pattern. The smell of fat is weak, specific. Visceral fat was significantly accumulated in the kidney area, less - along the entire mesentery and omentum. It has a dense consistency, crumbles when crushed, light gray on the omentum. In the large part of the intestine, it is darker, located in the form of layers, of a dense consistency (Fig. 2). The smell of fat is slightly sour, with a specific savor. In the molten state, the subcutaneous and visceral fat of sika deer is transparent.

From the physical properties of fat, the melting temperature was studied, the results of which are shown in Table 1 (*- table compiled on the basis of authors' own research).

Table 1. Melting temperature of water deer fat.

\begin{tabular}{|l|c|c|c|c|}
\hline \multirow{2}{*}{ Indicator name } & \multicolumn{2}{|c|}{ water deer, $\mathrm{n}-1$} & \multicolumn{2}{c|}{ sika deer, $\mathrm{n}-1$} \\
\cline { 2 - 5 } & $\begin{array}{c}\text { subcutane } \\
\text { ous fat }\end{array}$ & visceral fat & subcutaneous fat & visceral fat \\
\hline $\begin{array}{l}\text { Melting } \\
\text { temperature, } \mathrm{C}^{\circ}\end{array}$ & 40.0 & 45.4 & 41.5 & 47.5 \\
\hline
\end{tabular}

Analyzing the data presented in Table 1, it was found that the melting temperature of subcutaneous fat in water deer is lower than that of visceral fat, and also lower than that of sika deer, both subcutaneous and visceral fat.

\subsection{Qualitative indicators of fat of water deer and sika deer}

During chromatographic separation, the mass fraction of fatty acids was determined from the total fatty acids of subcutaneous and visceral fat of the studied deer, the data obtained are presented in Table 2 (*- table compiled on the basis of authors' own research). The 
difference in indicators is statistically unreliable due to the inability to obtain a larger number of samples from the rarest species of deer in the Primorsky Krai.

Table 2. Fatty acid composition of water and sika deer fat.

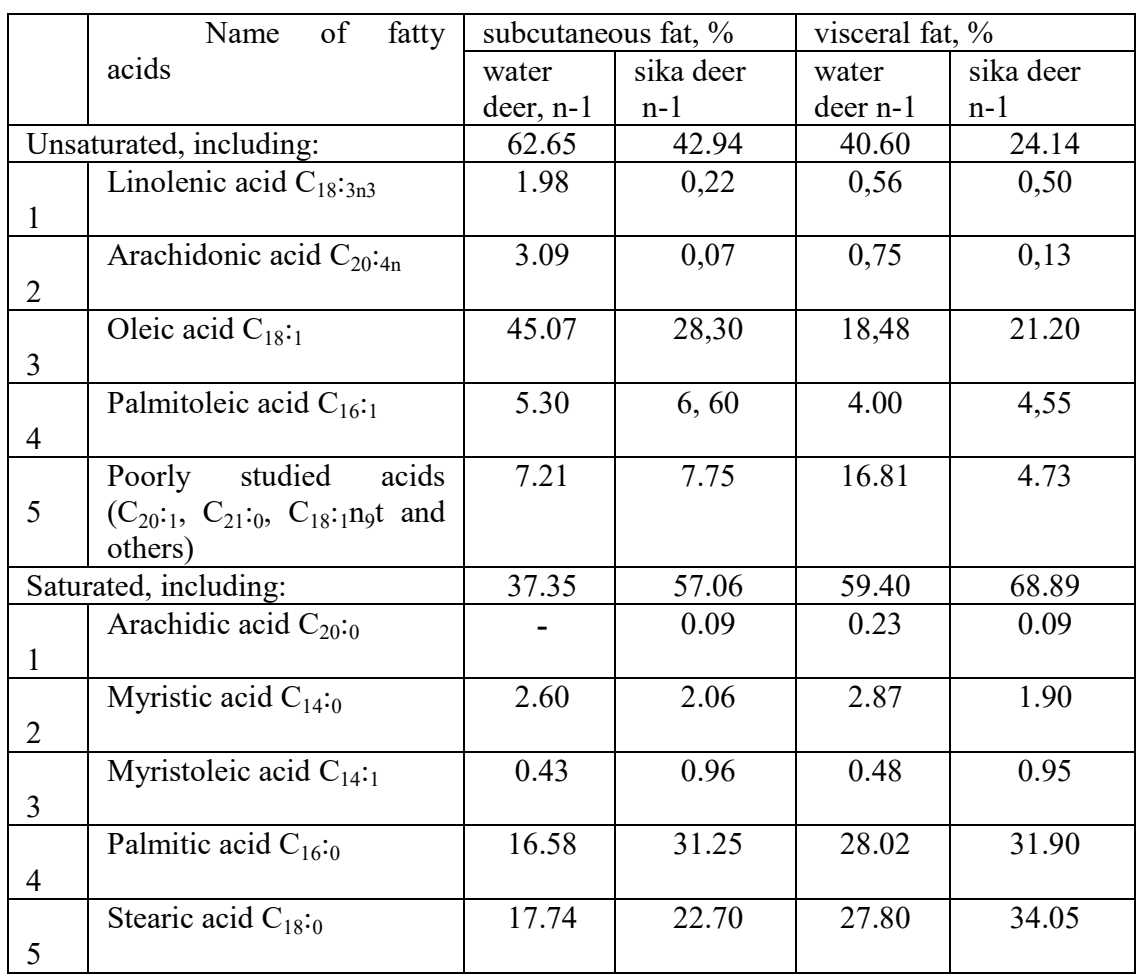

When analyzing the results of the study presented in Table 2, it was found that unsaturated fatty acids predominate in the subcutaneous fat of water deer, monounsaturated fatty acids predominate - oleic and palmitoleic, while the proportion of saturated fatty acids is almost two times less. Arachidonic, myristoleic and other poorly studied fatty acids have been found in relatively small amounts. In subcutaneous fat, the ratio of saturated to unsaturated fatty acids was 1:1.7. In visceral fat, most of the fatty acids are saturated acids, most of which are palmitic and stearic acids. A difference in the content of some fatty acids (palmitic, oleic, stearic) between subcutaneous and visceral fat was found, as well as in the total amount of saturated and unsaturated fatty acids of subcutaneous and visceral fat. In visceral fat, the ratio of unsaturated to saturated acids was 1:1.4.

In subcutaneous and visceral fat of sika deer, saturated fatty acids prevail. Their ratio was $1: 1.2$, and there are more unsaturated fatty acids in subcutaneous fat than in visceral fat - 1:1.7. In the subcutaneous fat of sika deer, unsaturated fatty acids are mainly represented by oleic acid, and there are less saturated acids, with a predominance of palmitic and stearic fatty acids. A similar picture is observed in the analysis of fatty acids in visceral fat, where palmitic and stearic acids predominate among saturated ones, and oleic acid -among unsaturated ones.

\section{Discussion}

In terms of organoleptic properties, water deer fat differs from sika deer fat by the absence of deposits among the muscular connective tissue layers in the studied individual, by a darker coloration of intestinal fat, and by the smell of fat. The melting temperature of 
visceral fat in water deer is $2.1^{\circ} \mathrm{C}$ lower than that in sika deer. The melting temperature of subcutaneous fat in water deer is $1.5{ }^{\circ} \mathrm{C}$ less than that of a similar fat in sika deer. Therefore, in terms of digestibility, water deer subcutaneous fat has an advantage over visceral fat, as well as over subcutaneous and visceral fat of sika deer.

Monounsaturated fatty acids predominate in subcutaneous fat of water deer, while saturated fatty acids predominate in subcutaneous fat of sika deer. The ratio of unsaturated fatty acids of subcutaneous fat in sika deer to unsaturated acids of similar fat in water deer was $1: 1.4$, and for visceral fat, this ratio was $1: 1.7$.

Monounsaturated fatty acids predominate in visceral fat of water deer, and saturated fatty acids predominate in visceral fat of sika deer.

The ratio of saturated fatty acids of subcutaneous fat in water deer to saturated acids of the same fat in sika deer was 1:1.5, and for visceral fat, this ratio was 1:1.1. At the same time, visceral fat of both animals contains the most stearic and palmitic acids (saturated), which are very valuable in nutritional terms. Compared to sika deer, fat of water deer contains more oleic acid, which ensures stability of the deposited lipids against oxidation with a moderate amount of antioxidants, which contributes to increased digestibility and imparts nutritional value to water deer fat.

\section{Findings}

1. Subcutaneous and visceral fat of water deer does not differ in consistency, but intestinal fat has a darker color and a sourer smell. Subcutaneous fat of sika deer does not differ from visceral fat in color, smell and consistency. The melting temperature of subcutaneous fat in water deer and sika deer is lower than the melting temperature of visceral fat, which corresponds to the available information of A.S. Bogachev [3] on the difference in the melting temperature of fat taken from different parts of the animal's body.

2. Monounsaturated fatty acids predominate in subcutaneous fat of water deer, and saturated fatty acids - in visceral fat. In subcutaneous and visceral fat of sika deer, saturated fatty acids predominate. In water deer, the ratio of saturated fatty acids of subcutaneous fat to visceral fat was 1:1.6, unsaturated - 1:1.5. In subcutaneous fat of sika deer, the ratio of unsaturated fatty acids to saturated ones was 1:1.3, in visceral fat - 1:2.8.

\section{Conclusion}

The rich composition of fatty acids in the lipids of water deer and sika deer is explained by the rich variety of food in their diet, including animal food. The physical properties and diverse composition of fatty acids characterize the fat of water and sika deer as a highquality dietary product that can be used both for food purposes and as a food base for big cats in Primorsky Krai - the Far Eastern leopard and the Amur tiger, which is especially important against the background of a decrease in the number of wild boars associated with the African swine fever virus epizootic. The results of the study can be used by veterinary specialists, biologists and game managers to identify the species of ungulates during forensic-veterinary (biological, zoological) examination, which creates the practical significance of this scientific work.

\section{References}

1. L.V. Lapshin, Animal world of the Far East (FSBEI HPE Primorskaya State Academy of Agriculture, Ussuriysk, 2014) 
2. S.V. Aramilev, State and development prospects of the population of the Ussuri sika deer (Census nippon hortulorum Swinhoe, 1864)

3. A.S. Bogachev, Bile of a bear, deer tail, deer musk, badger fat: characteristics, methods and processing, folk recipes (Ussuriysk, 1993)

4. https://www.researchgate.net/publication

5. Yu.A. Darman, Hydropotes inermis (Cervidae) - a new species for the fauna of Russia from the Land of the Leopard National Park (Russia), Nature Conservation Research 4, 3, 127-129 (2019)

6. P.V. Fomenko, Specialist's opinion on the species of the animal presented as a full-size stuffed animal, Amur branch of the World Wide Fund for Nature (2019)

7. https://animaldiversity.org/accounts/Hydropotes_inermis

8. https://citeseerx.ist.psu.edu

9. O.A. Dmitrieva, Fundamentals of examination of wild animals (Vladivostok: Apel'sin, 2012)

10. G.F. Baryshnikov, A.N. Tikhonov, Mammals of the fauna of Russia and adjacent territories. Ungulates. Part 1. Odd-toed and pair-toed (pig, musk deer, deer) (SPb.: Naula, 2009)

11. V.E. Sokolov, Taxonomy of mammals. Groups of cetaceans, carnivores, proboscideans, hyraxes, sirens, artiodactyls, tylopods, perissodactyls: textbook (M.: Higher school. 1979)

12. E.N. Lyubchenko, I.P. Korotkova, G.V. Ivanchuk, N.S. Kukharenko, R.A. Zhilin, A.A. Kozhushko, Morphometric studies of wild cats of the Far East: a tutorial (FSBEI HE Primorskaya State Academy of Agriculture, Ussuriysk, 2019)

13. G.V. Ivanchuk, Use of digital photography in forensic veterinary examination, Quality of education and innovation in agricultural universities of the Far Eastern Federal District: proceedings of the regional scientific and methodological conference, Ussuriysk, March 19-21 (2007)

14. E.A. Korotkov, Organoleptic and physicochemical properties of water deer fat, Proceedings of 56 All-Union scientific student conference, FGBEI HE Primorskaya State Academy of Agriculture, Ussuriysk (2020) 